\title{
Persistent pain of distal clavicle fractures with a large lateral angle acromion treated with a clavicle hook plate: Report on 9 cases
}

\author{
Kailun Wu \\ Soochow University \\ Hao Xu \\ Wujiang TCM Hospital \\ Yingjie Xu \\ Soochow University \\ Huilin Yang \\ Soochow University \\ Jiong Jiong Guo ( $\nabla$ drijguo@163.com ) \\ The First Affiliated Hospital of Soochow University
}

Research article

Keywords: distal clavicle fractures; clavicle hook plate; large lateral angle of acromion; distal clavicle-acromion coronal angle; subacromial impingement; rotator cuff lesion

Posted Date: October 4th, 2019

DOl: https://doi.org/10.21203/rs.2.15568/v1

License: (-) (i) This work is licensed under a Creative Commons Attribution 4.0 International License. Read Full License 


\section{Abstract}

Background: The clavicular hook plate was a popular surgical treatment for distal clavicle fractures. The relationship among characteristics of the hook plate, acromioclavicular joint morphology and clinical outcome has remained poorly understood. We reviewed the clinical records of patients who had distal clavicle fractures with large lateral angle of acromion treated using a clavicle hook plate and evaluated the feasibility of this technique.

Methods: Between 2010 and 2017, 9 patients (4 male and 5 female; mean age, 43 years) who had distal clavicle fractures with a large lateral angle of acromion were treated by clavicle hook plate at our institute. Follow-up ranged from 18 to 28 months (mean, 23 months). We examined clinical characteristics, MRI findings, treatments, and outcomes.

Results: All patients complained of implant-related symptoms postoperatively. Clinical subacromial impingement was observed in all of them. Two patients had relief after removing the device. The symptoms in the remaining seven patients did not subside after removal of plate. Rotator cuff lesions were found in these cases, five of whom received rotator cuff repair and achieved remission of their symptoms.

Conclusion: Distal clavicle-acromion coronal angle is an important factor for postoperative efficacy of the hook plate. The selection of a hook plate that makes the contact position between the hook and acromion more proximal may be helpful. Early limited mobility and removal of the implant may improve the prognosis and reduce the rate of impingement and rotator cuff lesions.

Study Design: Restropective Review, Level of evidence, 4.

\section{Background}

Distal clavicle fractures are mainly caused by indirect violence and account for approximately $21 \%$ of all clavicle fractures [1]. They are divided into three types according to the relationship of the fracture line to the coracoclavicular ligaments and acromioclavicular joint by Neer [2]. Type I occurs lateral to the coracoclavicular ligaments. Type II is characterized by a medial fracture with the coracoclavicular ligaments ruptured. Type III is an intraarticular fracture of the acromioclavicular joint. These fractures are well known as a high percentage of nonunion in the conservative treatment, particularly Neer type II. Therefore, surgical treatments have been recommended in order to improve clinical outcomes [3].

There are an array of surgical treatments in the literature including K-wire transfixation [4], tension band wires [5], coracoclavicular screw fixation [6], ligament repair or reconstruction [7] and clavicular hook plate. The clavicular hook plate was a popular surgical treatment, which can provide high stability for the acromioclavicular joint. Clinical research has demonstrated that both function and imaging evaluation were satisfactory after treating with a clavicular hook plate as defined by stable fixation, fast union and few complications [8]. However, there were still some complications such as acromial osteolysis, subacromial shoulder impingement, or even rotator cuff tear $[9,10]$.

To date, there have been many reports indicating postoperative pain and complications with use of the clavicular hook plate. A main concern was the relationship between position/ type of implant and complication, especially subacromial shoulder impingement and rotator cuff lesion $[10,11]$ Some studies recommended that it was unnecessary to remove the hook plate as soon as bony union was achieved $[10,11]$.

We believe that postoperative pain is closely related to the morphology and complex structure of the plate, distal clavicle and acromion, and not only the presence of the hook plate itself. Some research has speculated about the possibility of morphology of the acromioclavicular joint and impingement based on the sagittal diversity of acromioclavicular joint seen in the general population $[12,13]$.

In this study, we retrospectively reviewed 9 cases who had distal clavicle fractures with a large lateral angle of acromion treated using a clavicular hook plate. We defined a large lateral angle of acromion as a distal clavicle-acromion coronal angle $>40^{\circ}$ and an acromion-coronal angle $<60^{\circ}$ (this type is relatively infrequent in the general population) [14]. In addition, we provided a new 
method for measuring the distal clavicle-acromion coronal angle, which could make it more efficient in the application of the clavicular hook plate. Finally, to the best of our knowledge, this is the first report describing and analyzing the long-term outcome of surgical treatment of distal clavicle fractures with a large lateral angle of acromion using a clavicular hook plate.

\section{Methods}

Patient characteristics:

From January 2010 to August 2017, nine patients with a large lateral angle acromion who suffered from trauma-induced pain and limited movements of their shoulder were diagnosed in our trauma center (Department of Orthopedics, The First Affiliated Hospital of Soochow University; Suzhou City Wujiang Hospital of TCM) as distal clavicle fractures (type I in case 1, type II in the others, classified according to the Neer classification) (4 males and 5 females, average age 44.1 years, range 27-56 years). All preoperative $\mathrm{X}$-ray showed the obvious fracture displacement. With the failure of manual reposition, internal fixation must be performed on a reduced and aligned fracture (re-displacement occurred after 6 days in 2 cases). The common characteristics of these patients included a distal clavicle-acromion coronal angle $(\alpha)>40^{\circ}$, acromion-coronal angle $(\beta)<60^{\circ}$ and the inferior facet of acromion being particularly wide referring to the uninjured side. (Fig $1 \mathrm{~A}, \mathrm{~B}$ ) Classification and measurement of the acromioclavicular joint index were made at standardized true anteroposterior radiographs using X-rays with a resolution of 0.1 $\mathrm{mm}$. The above mentioned morphological parameters were measured using Digimizer Image Analysis Software. The exclusion criteria included: 1) bilateral clavicular fractures; 2) injured clavicle undergoing prior surgical treatments; 3) severe accompanying injury; 4) abnormal function before injury.

During the same period, we retrospectively analyzed supplementary 93 patients who had distal clavicle fractures with common lateral angle acromion $\left(\alpha<40^{\circ}\right.$ and $\left.\beta>60^{\circ}\right)$ for comparison. These cases were in accord on exclusion criteria, management principle and methods. In order to better describe it, they were divided into three groups based on angular variation (group A: $30^{\circ}<\alpha<40^{\circ}$ and $60^{\circ}<\beta<70^{\circ}$; group B: $20^{\circ}<\alpha<30^{\circ}$ and $70^{\circ}<\beta<80^{\circ}$; group C: $0^{\circ}<a<20^{\circ}$ and $80^{\circ}<\beta<90^{\circ}$ ).

All patients were treated with a clavicular hook plate. We defined the distal clavicle-acromion coronal angle as the incline angle between the upper surface of distal clavicle and the inferior facet of acromion on coronal plane, which was consistent with the practical situation of implanting the clavicular hook plate. (Fig 1 B) The acromion-coronal angle was then measured as the angle between the inferior facet of acromion and the line from the superior and inferior margin of the glenoid cavity on coronal plane, which presented intrinsic inclination of acromion. This study was approved by the Ethics Committee of our hospitals, and all patients provided written informed consent.

Surgical procedures:

All surgeries were performed by surgeons at our orthopaedic trauma centers (The First Affiliated Hospital of Soochow University and Suzhou City Wujiang Hospital of TCM) within one week (mean time, 3.2 days) after injury. Surgery was performed under general anesthesia and in the beach-chair position. A linear incision was made on the distal clavicle. After reduction and confirming of the subacromial space, the hook plate was placed under the acromion posterior to the acromioclavicular joint. Two different depths of hook ( $15 \mathrm{~mm} \& 18 \mathrm{~mm}$ ) were available. However, during surgery, a hook type of $18 \mathrm{~mm}$ was difficult to accommodate the thicknesses of the acromion with a large lateral angle. Unexpectedly, the fracture could not be reduced after positioning the clavicular hook plate in all cases, which manifested as the endpiece of the plate uplifted or a fracture shift. (Fig 1 C) Taking the contours of the bone into consideration, we tried a number of implants with different angles $\left(90^{\circ}, 95^{\circ}, 100^{\circ}, 105^{\circ}\right.$, and $\left.110^{\circ}\right)$. No matter how we configured the plate to the shape of clavicle, it turned out that the resistance of reduction increased with the bending angle enlarging. $\mathrm{A} 90^{\circ}$ or $95^{\circ}$ hook angle was ultimately accepted and fixed with screws.

\section{Postoperative management:}

The shoulder was kept in suspension fixation for one month and passive pendulum exercise was encouraged 3 days postoperatively with the aid of the uninjured arm. Ice compression was applied after functional exercise. Patients were required to take active exercise after 3 weeks. Six weeks postoperatively, active motion of over $90^{\circ}$ was permitted. Patients were followed 
up every 3 months thereafter to observe the recovery of shoulder function. After fractures healed, the patients were allowed to have removal of the hook plate.

Clinical Assessment:

Subacromial impingement was diagnosed according to Neer's impingement sign. The Japanese Orthopaedic Association (JOA) scoring system was used for functional assessment 3 months after internal fixation and removal of fixation [15]. This system was based on 100 points including pain assessment (30 points), shoulder function (20 points), range of movement (ROM) (30 points), radiographic evaluation (5 points) and joint stability (15 points). In accordance with the JOA shoulder assessment by Tomoya et al. [16], we defined functional recovery as a score more than $80 \%$ in each JOA shoulder assessment component. Magnetic resonance imaging (MRI) was performed if constant pain remained for 3 months after bony union and plate removal.

\section{Results}

The mean of a angle was $44.56^{\circ}$, while that of $\beta$ angle was $53.42^{\circ} .15 \mathrm{~mm}$ depth of hooks were used in all cases, and in three cases a $95^{\circ}$ of hook type was used. JOA Scores at 3 months postoperatively (mean 65.8) was lower than that at 3 months after removal (mean 75.7). However, one patient (case 1) was an exception before and after the removal with no difference. Radiography at the immediate postoperative period showed good fracture reduction. According to clinical and radiographic results, all fractures achieved bony union within 3 months after surgery. The clinical and demographic data were shown in Table 1.

Postoperatively, all patients complained of implant-related symptoms including pain, scraping feeling and limited motion of the operated shoulder. The clinical subacromial impingement (positive Neer's sign) was obeserved in all. Nevertheless, case 5 and 7 had relief gradually within approximately 2 months after implantation. The symptom of case 8 was relieved significantly after withdrawal of the plate. In contrast, unbearable pain was noted for daily life and work in the remaining 6 patients with the range of JOA from 50 to 65 points. Their symptoms did not subside (strength and ROM of shoulder was slightly improved, but with no signifcant differences in pain), even if undergoing early removal of the plate like case 1. A rotator cuff lesion was further confirmed eventually with the aid of MRI examation in these cases (Fig 2), five of whom received rotator cuff repair and achieved remission. At final follow-up, case 1 refused a second surgery and was lost to follow up.

Of the 93 included patients, eight (six in group $C$ and two in group B) refused to remove the internal fixation due to advanced age or family factors so that their conditions of rotator cuff cannot be detected. The mean time of hardware retention of remaining patients was respectively 8.8 months in group $C$ and 8.6 months in group B. Of particular note was exponential growth of rotator cuff lesion (RCL) rate as the $a$ angle increased. It was not hard to see that a large lateral angle $\left(a=40^{\circ} ; \beta=60^{\circ}\right)$ was a dividing line from Fig 3, which was consistent with the higher frequency of impingement. The clinical data of patients with common lateral angle acromion was recorded in Table 2.

\section{Discussion}

Recently, several studies have demonstrated the use of the clavicular hook plate as a priority for distal clavicle fracture, especially for Neer type II fracture, with respect to the achievement of rigid fixation and a high rate of fracture union $[3,9]$. Karduna et al. proved that the hook plate can provide stronger anti-deformation capacity than conventional fixation such as tension band wire [17]. However, other researchers have believed that the hook plate can exert adverse effects on subacromial tissues, including subacromial impingement, acromial osteolysis and rotator cuff tear. One cadaver study revealed that the placement of the implant should be repositioned based on the different types of the acromion, because the wrong position may cause subacromial impingement [13]. Another cadaver study also indicated that the designs of the hook plate in fact cannot keep pace with the changes of acromioclavicular joint morphology [18]. All the above suggested that appropriate selection of the clavicle hook plate correlated with prognosis closely. Only by combining the three factors of characteristics of hook plate (plate length, hook depth and hook angle), fracture pattern and acromioclavicular joint morphology into an organic whole, can the best therapeutic effect be realized. 
The literature has still lacked a clear understanding of the relationship between characteristics of hook plate and acromioclavicular joint morphology. To date, almost all studies focused on the importance of acromion sagittal angle, and neglected distal clavicle-acromion coronal angle [12,19,20]. Furthermore, conventional distal clavicle-acromion angle (measured from the central axis of the distal clavicle and acromion) was insufficient for practical requirements according to our experience. Therefore, we performed the current study to determine whether large lateral angle of acromion correlated with the severity of postoperative pain in treating distal clavicle fractures with a clavicular hook plate.

Type selection of clavicular hook plate:

Currently, clavicular hook plates still cannot match the anatomy of the distal clavicle and acromion perfectly [21]. For remedying the situation, a number of alternative characteristics of hook plate during the procedure, such as different plate length, hook depth and hook angle have been recommended. However, for some rare acromial morphology like large lateral angle of acromion, these characteristics cannot meet our demands.

In our study, only a plate equipped with a depth of $15 \mathrm{~mm}$ and small angle can barely accommodate the acromion with a large lateral angle. Interestingly, as the angle of implant increased, the resistance of reduction increased, which cannot be weakened by reshaping the plate. In our experience, this phenomenon was reflected obviously when $a>30^{\circ}$ and $\beta<70^{\circ}$. Lee and Shih et al. investigated the mechanics of the plate length and hook depth using finite element analysis (FEA) method and found that the stress on the acromion and clavicle was smaller when using a hook plate with greater length and depth [22,23]. Hung et al. also used FEA to investigate the impacts of different hook angles. They found that a larger hook angle of implant exerted a larger load on the acromion because the larger hook angle made the contact position between the hook plate and acromion more proximal [24]. This theory seemed to contradict the phenomenon we encountered. On the contrary, the contact position between the hook plate and acromion was in fact away from the proximal when using a larger depth and angle in large lateral angle of acromion. (Fig 4) Therefore, the hook plate was forced to be attached to the distal and proximal part of clavicle simultaneously, leading to excessive stress.

Paradoxically, a small angle and depth of hook plate may induce subacromial impingement more easily. Previous study has shown that the proximal clavicular hook was the main part compressing the supraspinatus tendon [11]. When using a small angle, the corner of the proximal hook was fallen lower, resulting in a larger contact area and force on the supraspinatus. Furthermore, as the distal clavicle-acromion coronal angle increased, the risk of proximal hook slippage may increase [12]. Therefore, at least in theory, we suggest that other schemes have to be taken into account when the a angle exceeds $10^{\circ}$. Whereas, from the observation in clinical practice, the a angle exceeding $30^{\circ}$ may be a clear indication.

Lateral angle of acromion and impingement:

In our research, all patients complained of a variety of pain related to impingement, especially when their arms were lifted over their head. In addition, seven patients who had shoulder impingement symptoms scored lower JOA scores and had poor satisfaction. At the end of this study, the impingements had developed into rotator cuff tear in these seven cases for an overall incidence of $77.8 \%$ ! In our supplementary cases, we have not found such a high rate of RCL, though the incidence had a tendency to increase with an increase in a angle.

Other investigators have also reported subacromial impingement and rotator cuff tear associated with implantation of a clavicular hook plate [9-11,13,25-30]. (Table 3) Of particular concerns were two articles. One study reported that incidence of subacromial shoulder impingement and rotator cuff lesion was calculated by dynamic sonographic evaluation, reaching as high as $37.5 \%$ and $15 \%$ [10]. Another one investigated 12 patients treated with hook plate by arthroscopic evaluation, and $91.7 \%$ of them developed signs of impingement [28]. Compared with the above, there was a far higher incidence of pain and rotator cuff tear in our research. We considered that the stress on supraspinatus tendon increased on account of the large lateral angle of acromion. Almost all studies have neglected the effect of distal clavicle-acromion coronal angle in the treatment of distal clavicular fracture, which was a significant factor impacting the outcome of the hook plate in our study.

To the best of our knowledge, the only solution to postoperative persistent pain was removal of the implant as soon as bony union has occurred. Leu et al. demonstrated that the impingement problems can disappeared within 8 weeks after removal [30]. 
Of our patients, the mean time of removal was 6.7 months, which was longer than the other studies. A shorter interval between union and plate removal might provide a key factor for preventing further development of impingement. As evidenced by our supplementary research, RCL did not occur for those undergoing removal surgery within half years after operation in group A, B and $\mathrm{C}$. In addition, early excessive mobility of the acromioclavicular joint may be another reason for developing a rotator cuff lesion in patients with a large lateral angle of acromion. According to a study by Kashii et al. [25], patients should avoid forward flexion or adduction greater than $90^{\circ}$ and internal rotation of the shoulder behind the back until the hook plate is removed.

A limitation of this study was the small number of patients with a large lateral angle acromion. Further studies with a larger number of cases are needed. Another limitation of this study was that we did not carry out a comprehensive analysis for the all types of distal clavicle fracture. Besides, we cannot be certain that there is a variation of this angle between left and right sides in a single individual. Similarly, while one may assume the impingement from the plate cause the rotator cuff tear this study, as it is designed, cannot establish causation. In order to establish causation the patients each would have had to have an ultrasound or MRI before fracture fixation or the injury. But it is unlikely to perfect interrelated examinations before the injury. Lastly, a separate analysis of the hook plate was incomplete. Instead, a comprehensive accessment was available only by comparing a variety of procedures.

\section{Conclusions}

Nine cases of distal clavicle fractures with a large lateral angle of acromion were treated. Persistent pain caused by impingement or rotator cuff tear occurred. Firstly, although the number of cases was small, we have demonstrated that the distal clavicleacromion coronal angle is an important factor for postoperative efficacy of the hook plate. Secondly, the selection of characteristics of hook plate should make the contact position between the hook and acromion more proximal. Thirdly, early limited mobility and removal of the implant may improve the prognosis and reduce the rate of impingement and rotator cuff lesions. In our opinion in patients with a large lateral angle of acromion, other surgical fixation should be considered as the hook plate has a high complication rate despite achieving union of the fracture.

\section{Abbreviations}

JOA: Japanese Orthopaedic Association; ROM: Range Of Movement; MRI: Magnetic Resonance Imaging; RCL: Rotator Cuff Lesion; FEA: Finite Element Analysis.

\section{Declarations}

\section{Ethics approval and consent to participate}

The local ethical committee reviewed and delegated the approval of this study to the Data Protection Official at the First Affiliated Hospital of Soochow University and Suzhou City Wujiang Hospital of TCM who granted the ethics approval.

\section{Consent to publish}

Written informed consent was obtained from patients themselves for publication, along with any accompanying images. A copy of the written consent is available for review by the Editor of this journal.

\section{Availability of data and materials}

All data concerning the cases are presented in the manuscript or in supplementary material. In order to protect patients' privacy and respect confidentiality, the datasets have not been made available in public repositories. The original reports, laboratory examinations, imagings and outpatient clinic records are remained as per normal procedure in the medical records of our institutions. 


\section{Competing interests}

The authors declare that they have no competing interests.

\section{Funding}

There was no funding source.

\section{Authors' contributions}

KLW and JJG designed this paper and drafted the manuscript. HX and KLW collected the data and prepared figures. YJXand HLY performed edition. We confirm that all authors have the appropriate permissions and rights to the reported data. All authors have read and approved the manuscript.

\section{Acknowledgements}

Not applicable.

\section{Authors' Information}

${ }^{1}$ Department of Orthopedics, Suzhou Dushuhu Hospital (Dushuhu Hospital Affiliated to Soochow University), Suzhou, China. ${ }^{2}$ Department of Orthopedics, Suzhou City Wujiang Hospital of TCM. ${ }^{3}$ Department of Orthopedics, The First Affiliated Hospital of Soochow University, Suzhou, China.

\section{References}

1. Nordqvist A, Petersson C (1994) The incidence of fractures of the clavicle. Clin Orthop Relat Res 300:127-132. http://dx.doi.org/10.1034/j.1600-0501.1994.050106.x.

2. Nd NC (1968) Fractures of the distal third of the clavicle. Clin Orthop Rel Res 58:43.

3. Rahul B, Brian W, Jeff P, William R (2011) Management of distal clavicle fractures. J Am Acad Orthop Surg 19(7):392. http://dx.doi.org/10.3109/17453671003667168.

4. Shyu-Jye W, Chih-Shung W (2008) Extra-articular knowles pin fixation for unstable distal clavicle fractures. J Trauma Acute Care Surg 64:1522-1527. http://dx.doi.org/10.1097/ta.0b013e3180593646.

5. Badhe SP, Lawrence TM, Clark DI (2012) Tension band suturing for the treatment of displaced type 2 lateral end clavicle fractures. Arch Orthop Trauma Surg 127:25-28. http://dx.doi.org/10.1007/s00402-006-0197-3.

6. Zhe JC, Hyun-Kon K, Byoung-Hyun M (2006) Surgical treatment for distal clavicle fracture associated with coracoclavicular ligament rupture using a cannulated screw fixation technique. J Trauma 60:1358-1361. http://dx.doi.org/10.1097/01.ta.0000220385.34197.f9.

7. Yagnik GP, Porter DA, Jordan CJ (2018) Distal Clavicle Fracture Repair Using Cortical Button Fixation With Coracoclavicular Ligament Reconstruction. Arthroscopy Techniques 7(4):e411-415. http://dx.doi.org/10.1016/j.eats.2017.10.012.

8. Arirachakaran A, Boonard M, Piyapittayanun P, Phiphobmongkol V, Chaijenkij K, Kongtharvonskul J (2016) Comparison of surgical outcomes between fixation with hook plate and loop suspensory fixation for acute unstable acromioclavicular joint dislocation: a systematic review and meta-analysis. Eur J Orthop Surg Tr 26:565-574. http://dx.doi.org/10.1007/s00590016-1797-4. 
9. Renger RJ, Roukema GR, Reurings JC, Raams PM, Font J, Verleisdonk EJMM (2009) The clavicle hook plate for Neer type II lateral clavicle fractures. J Orthop Trauma 23:570-574. http://dx.doi.org/10.1097/bot.0b013e318193d878.

10. Lin HY, Wong PK, Ho WP, Chuang TY, Liao YS, Wong CC (2014) Clavicular hook plate may induce subacromial shoulder impingement and rotator cuff lesion - dynamic sonographic evaluation. J Orthop Surg Res 9:6-6. http://dx.doi.org/10.1186/1749-799X-9-6.

11. Gu X, Cheng B, Sun J, Tao K (2014) Arthroscopic evaluation for omalgia patients undergoing the clavicular hook plate fixation of distal clavicle fractures. J Orthop Surg Res 9:1-7. http://dx.doi.org/10.1186/1749-799X-9-46.

12. Shen PC, Zhu Y, Zhang H, Zhu LF, Weng FB, Jiang FG et al. (2017) Three-dimensional morphological analysis of acromioclavicular joint in patients with and without subacromial erosion after hook plate fixation. J Int Med Res 46(1):511521. http://dx.doi.org/10.1177/0300060517725973.

13. Elmaraghy AW, Devereaux MW, Ravichandiran K, Agur AM (2010) Subacromial morphometric assessment of the clavicle hook plate. Injury-Int J Care Inj 41:613-619. http://dx.doi.org/ 10.1016/j.injury.2009.12.012.

14. Shah NN, Bayliss NC, Malcolm A (2001) Shape of the acromion: Congenital or acquired-A macroscopic, radiographic, and microscopic study of acromion. J Shoulder Elb Surg 10:309-316. http://dx.doi.org/10.1067/mse.2001.114681.

15. Ide J, Maeda S, Takagi K (2005) A Comparison of Arthroscopic and Open Rotator Cuff Repair. Arthroscopy-the Journal of Arthroscopic \& Related Surgery 21:1090-1098. http://dx.doi.org/10.1016/j.arthro.2005.05.010.

16. Tomoya M, Yoichi I, Isshin M, Kunio T, Hiroaki N (2011) Functional recovery period after arthroscopic rotator cuff repair: is it predictable before surgery? Clin Orthop Relat Res 469:1660-1666. http://dx.doi.org/10.1007/s11999-010-1689-6.

17. Karduna AR, Williams GR, Williams JL, lannotti JP (2010) Kinematics of the glenohumeral joint: influences of muscle forces, ligamentous constraints, and articular geometry. J Orthop Res: Official Publication of the Orthopaedic Research Society 14(6):986-993. http://dx.doi.org/10.1002/jor.1100140620.

18. Deng Z, Cai L, Ping A, Ai Q, Wang Y (2014) Anatomical research on the subacromial interval following implantation of clavicle hook plates. Int J Sports Med 35:857-862. 10.1055/s-0034-1367050. http://dx.doi.org/10.1055/s-00341367050.

19. Natsis K, Tsikaras P, Totlis T, Gigis I, Skandalakis P, Appell HJ et al (2007) Correlation between the four types of acromion and the existence of enthesophytes: a study on 423 dried scapulas and review of the literature. Clin Anat 20:267-272. http://dx.doi.org/10.1002/ca.20320.

20. Roidis NT, Soheil M, Suketu V, Edward E, Karachalios TS, Itamura JM (2009) The influence of the acromioclavicular joint degeneration on supraspinatus outlet impingement and the acromion shape. J Orthop Surg 17:331-334. http://dx.doi.org/10.1177/230949900901700318.

21. Zhang C, Huang J, Luo Y, Sun H (2014) Comparison of the efficacy of a distal clavicular locking plate versus a clavicular hook plate in the treatment of unstable distal clavicle fractures and a systematic literature review. Int Orthop 38:1461-1468. http://dx.doi.org/10.1007/s00264-014-2340-z.

22. Lee CH, Shih CM, Huang KC, Chen KH, Hung LK, Su KC (2016) Biomechanical Analysis of Implanted Clavicle Hook Plates With Different Implant Depths and Materials in the Acromioclavicular Joint: A Finite Element Analysis Study. Artif Organs 40:1062-1070. http://dx.doi.org/10.1111/aor.12679.

23. Shih CM, Huang KC, Pan CC, Lee CH, Su KC (2015) Biomechanical analysis of acromioclavicular joint dislocation treated with clavicle hook plates in different lengths. Int Orthop 39:2239-2244. http://dx.doi.org/10.1007/s00264-015-2890-8.

24. Hung LK, Su KC, Lu WH, Lee CH (2017) Biomechanical analysis of clavicle hook plate implantation with different hook angles in the acromioclavicular joint. Int Orthop 41:1-7. http://dx.doi.org/10.1007/s00264-016-3384-z.

25. Kashii M, Inui H, Yamamoto K (2006) Surgical treatment of distal clavicle fractures using the clavicular hook plate. Clin Orthop Rel Res 447:158-164. http://dx.doi.org/10.1097/01.blo.0000203469.66055.6a.

26. Muramatsu K, Shigetomi M, Matsunaga T, Murata Y, Taguchi T (2007) Use of the AO hook-plate for treatment of unstable fractures of the distal clavicle. Arch Orthop Trauma Surg 127:191-194. http://dx.doi.org/10.1007/s00402-006-0284-5.

27. Meda PVK, Bhuvaneswar M, Chris S, Ian B, Peter B, Frostick SP (2006) Clavicular hook plate for lateral end fractures:- a prospective study. Injury-Int J Care Inj 37:277-283. http://dx.doi.org/10.1016/j.injury.2005.10.017. 
28. Lee YS, Lau MJ, Tseng YC, Chen WC, Kao HY, Wei JD (2009) Comparison of the efficacy of hook plate versus tension band wire in the treatment of unstable fractures of the distal clavicle. Int Orthop 33:1401-1405.

http://dx.doi.org/10.1007/s00264-008-0696-7.

29. Tzu-Liang H, Shao-Keh H, Hsueh-Ming C, Shih-Tien W (2010) Comparison of hook plate and tension band wire in the treatment of distal clavicle fractures. Orthopedics 33(12):879. http://dx.doi.org/10.3928/01477447-20101021-04.

30. Leu T-H, Ho W-P, Wong P-K, Chuang T-Y, Wong C-C (2012) Clavicular Hook Plate: A Better Implant Choice for Fixation of Unstable Distal Clavicle Fractures? Int J Clin Exp Med 4:270-274. http://dx.doi.org/10.1016/j.jecm.2012.09.002.

\section{Tables}

Table 1. Summary of our cases of distal clavicle fractures with large lateral angle of acromion

\begin{tabular}{|c|c|c|c|c|c|c|c|c|c|c|}
\hline \multirow{2}{*}{$\begin{array}{l}\text { Case } \\
\text { No }\end{array}$} & \multirow{2}{*}{$\begin{array}{c}\text { Age, } \\
\text { y/ } \\
\text { Sex }\end{array}$} & \multirow[t]{2}{*}{ Side } & \multirow[t]{2}{*}{$\alpha$} & \multirow[t]{2}{*}{$\beta$} & \multirow{2}{*}{$\begin{array}{l}\text { Specification } \\
\text { (depth and } \\
\text { angle of } \\
\text { hook, mm) }\end{array}$} & \multicolumn{3}{|c|}{ Postoperative recovery } & \multirow{2}{*}{$\begin{array}{l}\text { Total } \\
\text { follow- } \\
\text { up time } \\
\text { (month) }\end{array}$} & \multirow{2}{*}{$\begin{array}{c}\text { Treatment } \\
\text { and outcome }\end{array}$} \\
\hline & & & & & & $\begin{array}{c}\text { JOA Scores } \\
(3 \\
\text { months postoperatively) }\end{array}$ & $\begin{array}{l}\text { Time of } \\
\text { hardware } \\
\text { retention } \\
\text { (month) }\end{array}$ & $\begin{array}{l}\text { JOA Scores } \\
\text { (3 } \\
\text { months after } \\
\text { removal) }\end{array}$ & & \\
\hline 1 & $30 / \mathrm{M}$ & Left & 49.1 & 40.6 & $15,90^{\circ}$ & 62 & 5 & 60 & 18 & $\begin{array}{l}\text { Untreated, } \\
\text { lost to follow- }\end{array}$ \\
\hline 2 & $52 / F$ & Right & 44.7 & 52.4 & $15,95^{\circ}$ & 65 & 6 & 75 & 28 & RCR, \\
\hline 3 & $27 / F$ & Right & 41.5 & 56.8 & $15,95^{\circ}$ & 55 & 7 & 75 & 23 & $\begin{array}{l}\mathrm{RCR}, \\
\text {, }\end{array}$ \\
\hline 4 & $44 / \mathrm{M}$ & Right & 47.8 & 54.8 & $15,90^{\circ}$ & 50 & 9 & 62 & 27 & RCR, \\
\hline $\begin{array}{l}5 \\
6\end{array}$ & $\begin{array}{l}46 / \mathrm{F} \\
39 / \mathrm{F}\end{array}$ & $\begin{array}{l}\text { Right } \\
\text { Left }\end{array}$ & $\begin{array}{l}45.1 \\
44.1\end{array}$ & $\begin{array}{l}44.5 \\
59.7\end{array}$ & $\begin{array}{l}15,90^{\circ} \\
15,90^{\circ}\end{array}$ & $\begin{array}{l}88 \\
65\end{array}$ & $\begin{array}{l}7 \\
5\end{array}$ & $\begin{array}{l}95 \\
70\end{array}$ & $\begin{array}{l}20 \\
24\end{array}$ & remission \\
\hline $\begin{array}{l}7 \\
8\end{array}$ & $\begin{array}{l}38 / \mathrm{M} \\
55 / \mathrm{F}\end{array}$ & $\begin{array}{l}\text { Left } \\
\text { Right }\end{array}$ & $\begin{array}{l}42.2 \\
40.4\end{array}$ & $\begin{array}{l}53.5 \\
58.9\end{array}$ & $\begin{array}{l}15,90^{\circ} \\
15,90^{\circ}\end{array}$ & $\begin{array}{l}83 \\
70\end{array}$ & $\begin{array}{l}7 \\
6\end{array}$ & $\begin{array}{l}96 \\
82\end{array}$ & $\begin{array}{l}21 \\
22\end{array}$ & $\begin{array}{l}\text { remission } \\
\text { Untreated, } \\
\text { partial }\end{array}$ \\
\hline 9 & $56 / \mathrm{M}$ & Right & 46.2 & 59.6 & $15,95^{\circ}$ & 54 & 8 & 66 & 24 & $\begin{array}{l}\text { remission } \\
\text { RCR, } \\
\text { remission }\end{array}$ \\
\hline
\end{tabular}

Table 2. General and postoperative clinical data of cases of distal clavicle fractures with common and large lateral angle of acromion

\begin{tabular}{|c|c|c|c|c|c|c|c|c|c|}
\hline & & $\mathrm{N}$ & $\underset{y}{\text { Age, }}$ & $\begin{array}{l}\text { Sex, } \\
\mathrm{M} / \mathrm{F}\end{array}$ & $\alpha$ & $\beta$ & $\begin{array}{l}\text { Neer } \\
\text { type } \\
\text { (I/II) }\end{array}$ & $\begin{array}{l}\text { Time of hardware } \\
\text { retention (month) }\end{array}$ & $\begin{array}{l}\text { Impingement } \\
\text { rate \& RCL rate }\end{array}$ \\
\hline \multirow{3}{*}{$\begin{array}{l}\text { Cases with common lateral } \\
\text { angle of acromion }\end{array}$} & Group & 56 & 39.4 & $25 / 31$ & 11.65 & 83.34 & $11 / 45$ & 8.8 & \multirow{4}{*}{$\begin{array}{c}16 / 56(28.6 \%) \& \\
2 / 50(4.0 \%) \\
8 / 21(38.1 \%) \& \\
1 / 19(5.3 \%) \\
10 / 16(62.5 \%) \& \\
3 / 16(18.8 \%) \\
9 / 9(100 \%) \& 7 / 9 \\
(77.8 \%)\end{array}$} \\
\hline & $\underset{B}{\text { Group }}$ & 21 & 42.6 & $12 / 9$ & 23.86 & 75.15 & $4 / 17$ & 8.6 & \\
\hline & Group & 16 & 44.3 & $9 / 7$ & 34.12 & 66.62 & $2 / 14$ & 7.5 & \\
\hline $\begin{array}{c}\text { Cases with large lateral angle } \\
\text { of acromion }\end{array}$ & & 9 & 44.1 & $4 / 5$ & 44.56 & 53.42 & $1 / 8$ & 6.7 & \\
\hline
\end{tabular}

Table 3. Summary of reported studies related subacromial impingement treating with clavicular hook plate. 


\begin{tabular}{|c|c|c|c|c|c|c|}
\hline $\begin{array}{c}\text { Author, } \\
\text { Reference }\end{array}$ & Year & $\begin{array}{l}\text { Study } \\
\text { design }\end{array}$ & $\begin{array}{c}\text { Case no. } \\
\text { (M/F) }\end{array}$ & $\begin{array}{l}\text { Duration of follow-up } \\
\text { (mean, month) }\end{array}$ & $\begin{array}{c}\text { Impingement rate } \\
\text { \& RCL rate }\end{array}$ & $\begin{array}{l}\text { Hardware removal (time after } \\
\quad \text { fixation operation, N) }\end{array}$ \\
\hline $\begin{array}{c}\text { Kashii et } \\
\text { al. }^{23}\end{array}$ & 2006 & $\begin{array}{l}\text { Case } \\
\text { series }\end{array}$ & $\begin{array}{c}34 \\
(28 / 6)\end{array}$ & 12.4 & $2 / 34$ (5.9\%) & 5.3 \\
\hline $\begin{array}{l}\text { Muramatsu } \\
\text { et al. }\end{array}$ & 2007 & $\begin{array}{l}\text { Case } \\
\text { series }\end{array}$ & $\begin{array}{c}15 \\
(13 / 2)\end{array}$ & 15.5 & $0 / 15(0 \%)$ & $4.5,12$ \\
\hline $\begin{array}{l}\text { Meda et } \\
\text { al. }^{25}\end{array}$ & 2006 & $\begin{array}{l}\text { Case } \\
\text { series }\end{array}$ & $\begin{array}{c}31 \\
(24 / 7)\end{array}$ & 40 & $6 / 31(19.4 \%)$ & 5.56 \\
\hline $\begin{array}{l}\text { Renger et } \\
\text { al. }^{8}\end{array}$ & 2009 & $\begin{array}{l}\text { Case } \\
\text { series }\end{array}$ & $\begin{array}{c}44 \\
(29 / 15)\end{array}$ & 27.4 & $33 / 44(75 \%)$ & 8.4 \\
\hline Lee et al. ${ }^{26}$ & 2009 & $\begin{array}{l}\text { Case } \\
\text { series }\end{array}$ & $\begin{array}{c}32 \\
(14 / 18)\end{array}$ & 26.4 & $0 / 32(0 \%)$ & $4.8,32$ \\
\hline $\begin{array}{l}\text { ElMaraghy } \\
\text { et al. }^{12}\end{array}$ & 2010 & $\begin{array}{l}\text { Cadaveric } \\
\text { studies }\end{array}$ & $15(7 / 8)$ & NA & $9 / 15(60 \%)$ & NA \\
\hline Hsu et al. ${ }^{27}$ & 2010 & $\begin{array}{l}\text { Case } \\
\text { series }\end{array}$ & $\begin{array}{c}35 \\
(23 / 12)\end{array}$ & 6 & $\begin{array}{c}9 / 35(25.7 \%) \& \\
0 / 35(0 \%)\end{array}$ & 12,35 \\
\hline Leu et al. ${ }^{28}$ & 2012 & $\begin{array}{l}\text { Case } \\
\text { series }\end{array}$ & $\begin{array}{c}25 \\
25 \\
(13 / 12)\end{array}$ & 14.5 & $9 / 25(36 \%)$ & $5.8,25$ \\
\hline Lin et al. ${ }^{9}$ & 2014 & $\begin{array}{l}\text { Case } \\
\text { series }\end{array}$ & $\begin{array}{l}40 \\
(30 / 10)\end{array}$ & 13.6 & $\begin{array}{c}15 / 40(37.5 \%) \& \\
6 / 40(15 \%)\end{array}$ & $5.78,40$ \\
\hline Gu et al. ${ }^{10}$ & 2014 & $\begin{array}{l}\text { Case } \\
\text { series }\end{array}$ & $12(7 / 5)$ & NA & $\begin{array}{l}11 / 12(91.7 \%) \\
1 / 12(8.3 \%)\end{array} \&$ & NA, 12 \\
\hline Our cases & - & $\begin{array}{l}\text { Case } \\
\text { series }\end{array}$ & $9(4 / 5)$ & 23 & $\begin{array}{c}9 / 9(100 \%) \& 7 / 9 \\
(77.8 \%)\end{array}$ & $6.7,9$ \\
\hline
\end{tabular}

\section{Figures}



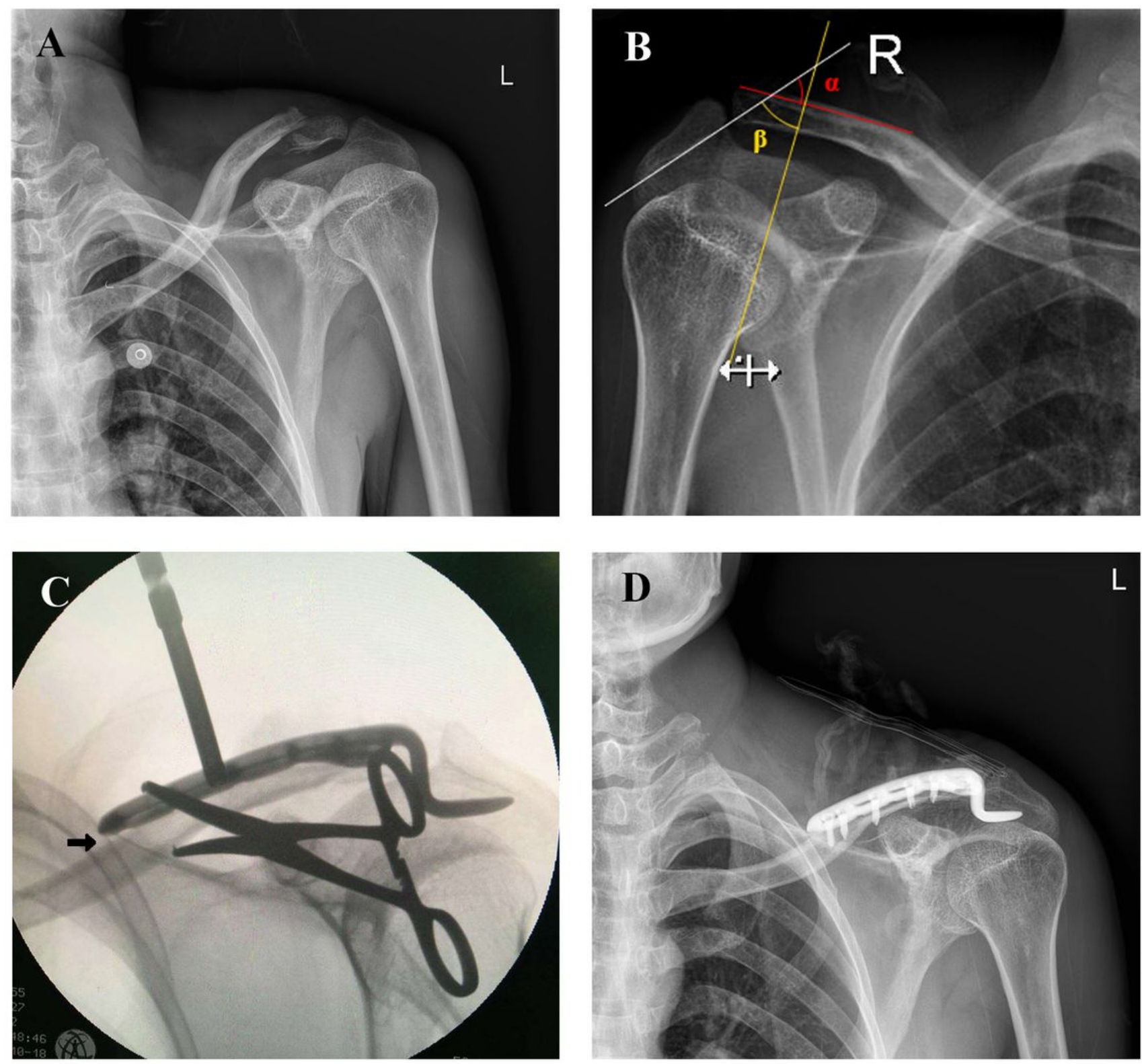

Figure 1

Case 1. A 30 year-old man with left distal clavicle fracture treated with clavicular hook plate. (A) Preoperative radiography indicated Neer type I fracture of the distal clavicle. (B) distal clavicle-acromion coronal angle ( $\mathrm{a}$ ) and acromion-coronal angle ( $\beta$ ) on X-ray films of uninjured side. (C) Intraoperative fluoroscopy showed the endpiece of plate uplifted (black arrow). (D) Postoperative $\mathrm{X}$-ray demonstrated accepted fracture reduction. 

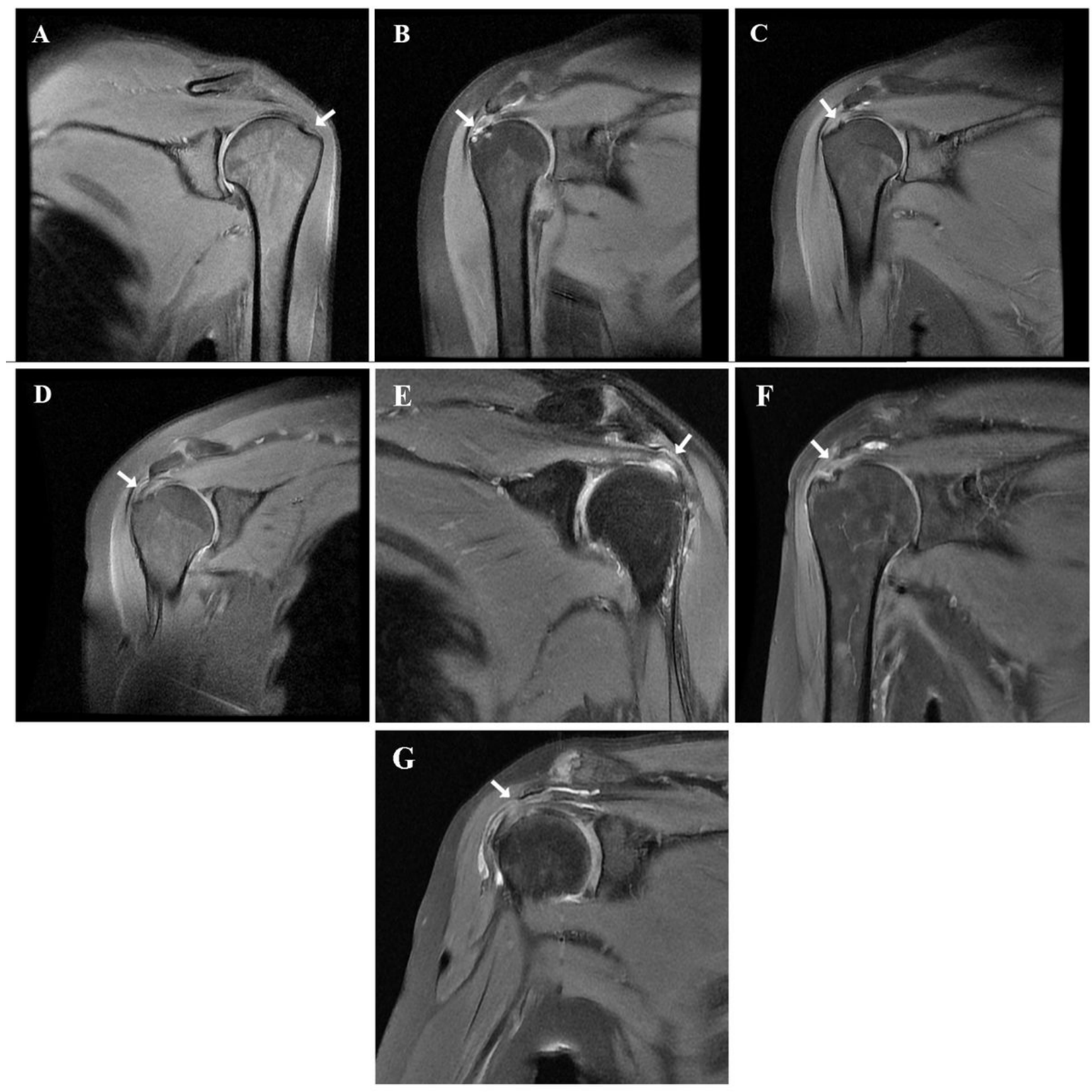

Figure 2

(A, B, C, D, E, F, G) Case 1 4, 6, 8 9. Preoperative sagittal T2-weighted magnetic resonance (MR) imaging reveals the interruption of supraspinatus tendon continuity (white arrows). 


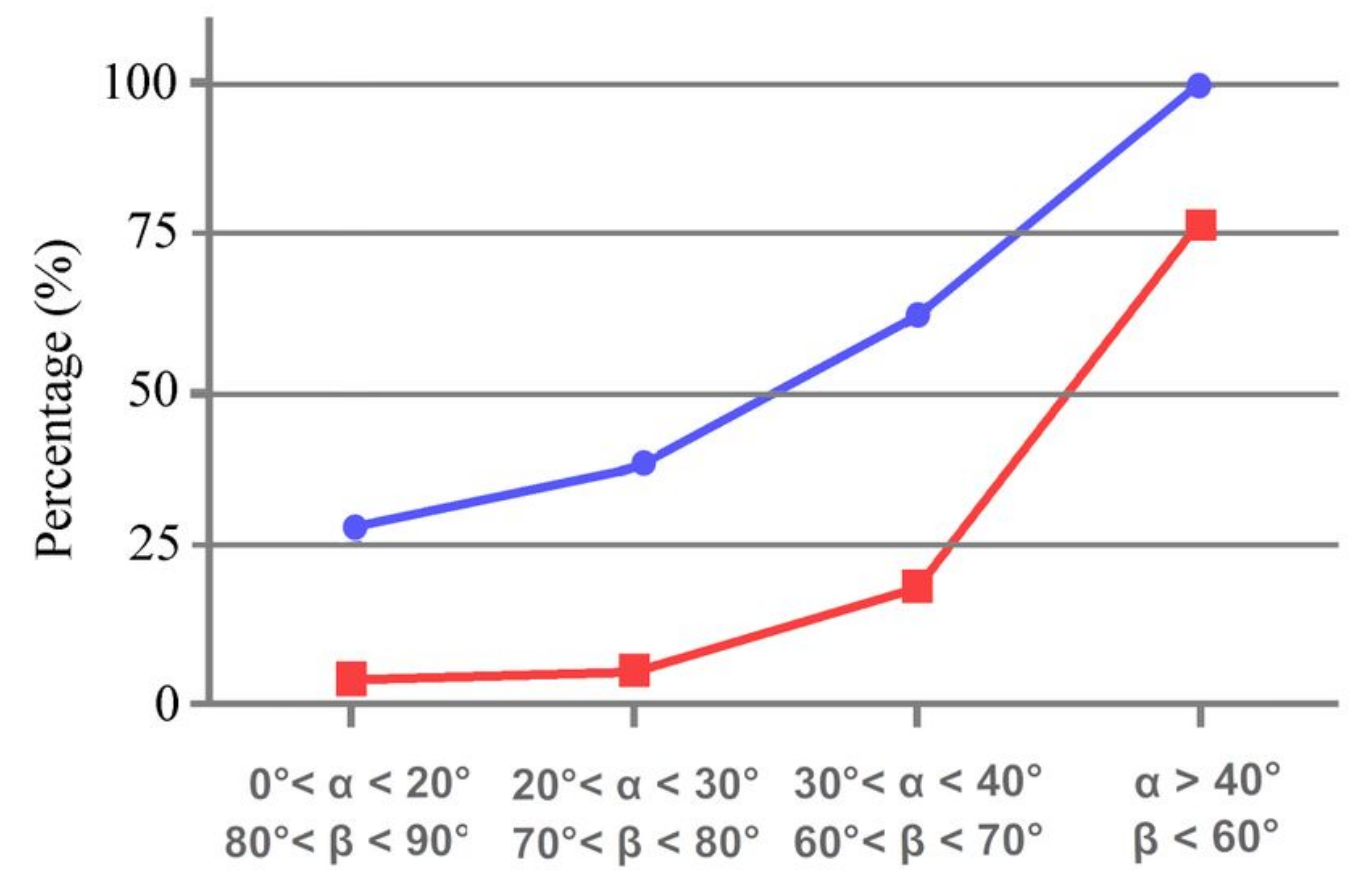

- Impingement rate

RCL rate

Figure 3

Graphic presentation of impingement \& RCL rates correlated with a \& $\beta$ angles. 


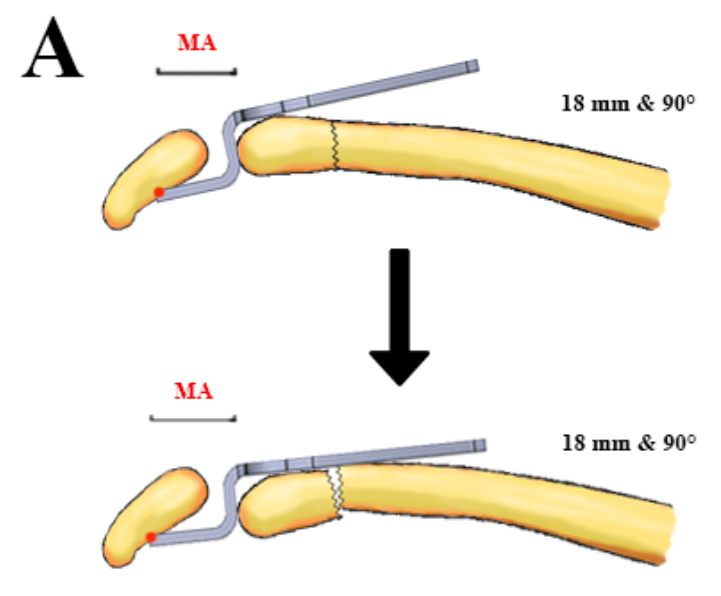

C

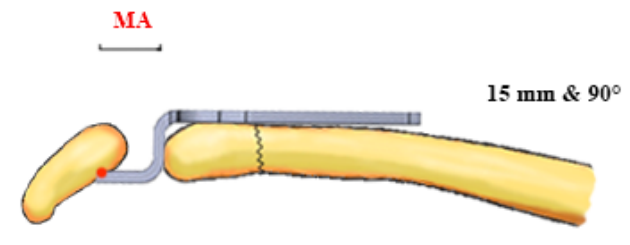

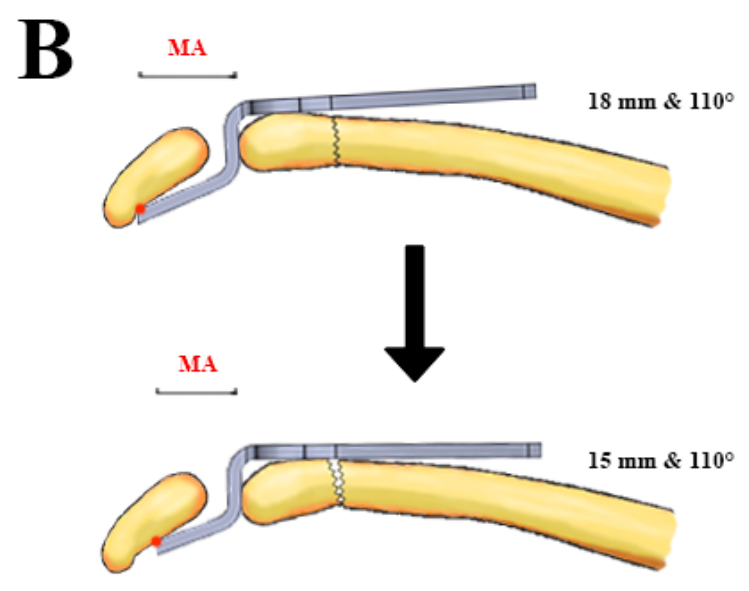

D

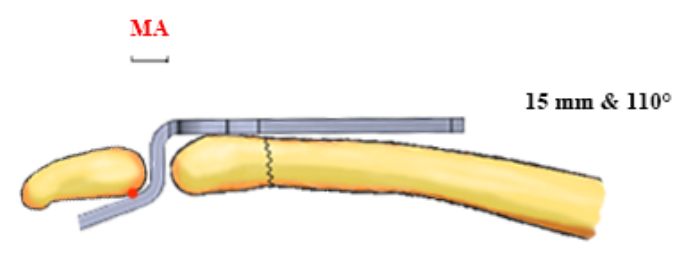

\section{Figure 4}

$(A, B, C)$ The situation of dynamic simulating the changes of contact position between the hook plate and large lateral angle of acromion. (A) The change of contact position (red dot) when using large depth (18 mm). (B) The change of contact position (red dot) when using large angle $\left(110^{\circ}\right)$. (C) The situation of small angle and depth $\left(90^{\circ} \& 15 \mathrm{~mm}\right)$ and the moment arm (MA) is shortest. (D) The contact position (red dot) and MA between the hook plate and normal lateral angle of acromion. 